\title{
O potencial teórico do conceito de midiatização e os estudos sobre classes sociais na comunicação
}

\author{
Rafael Grohmann \\ Doutorando e mestre em Ciências da \\ Comunicação pela Universidade de São \\ Paulo (USP). Professor do Programa de \\ Mestrado Profissional em Jornalismo \\ do FIAM - FAAM - Centro Universitário \\ e do curso de Jornalismo da Faculdade \\ Cásper Líbero. Membro do Centro de \\ Pesquisas em Comunicação e Trabalho \\ (CPCT - ECA/USP). \\ E-mail: rafael-ng@uol.com.br
}

\section{Rosana Mauro}

Doutoranda e mestre em Ciências da Comunicação pela Universidade de São Paulo - USP.

E-mail: mauro.rosana@gmail.com
Resumo: O texto busca compreender como o conceito de midiatização tem sido abordado em suas diferentes tradições de estudo e discutir o seu potencial teórico para estudar as classes sociais na Comunicação. Para tanto, discutimos: a) as classes sociais como tema da comunicação; b) as diferentes abordagens do conceito de midiatização; c) as relações entre os conceitos de midiatização e mediação, procurando mostrar o que significa estudar as classes sociais a partir de cada conceito.

Palavras-chave: Midiatização; Conceito; Comunicação; Mediação; Classe.

Title: The theoretical potential of the mediatization's concept and the studies on social classes in the comunication

Abstract: The paper aims to understand how the concept of mediatization has been addressed in their different traditions of study and discuss its theoretical potential to understand the social class in communication. To this end, we discuss: a) social classes as a subject of communication; b) the different approaches to the concept of mediatization; $c$ ) the relationships between the concepts of mediation and mediatization, trying to show what it means to study the social classes from each concept.

Keywords: Mediatization; Concept; Communication; Mediation; Class. 


\section{Introdução}

Os conceitos funcionam na ciência como zeitgeists teóricos: expressam o espírito do tempo em um determinado campo, que revelam marcas de hegemonias e embates, tanto pela visibilidade de um conceito quanto pela supremacia semântica de como tal termo merece ser consolidado. No campo teórico da Comunicação não é diferente.

Se nos anos 1990 e no início dos anos 2000, o conceito de mediação era uma referência quase obrigatória nos debates comunicacionais brasileiros, principalmente a partir dos escritos de Jesús Martín-Barbero (2009), nos últimos anos, outros conceitos parecem ganhar maior destaque nas discussões da área, como os de "midiatização" e "circulação", sobretudo para pesquisas com escopo nas diferentes relações entre mídia/comunicação e sociedade, como mostram Lelo e Grohmann (2014) a partir do conceito de circulação e Mattos, Janotti Junior e Jack (2012) a partir dos conceitos de mediação e midiatização.

Como diz Sonia Livingstone (2009), se antes as pesquisas em Comunicação tinham sempre um meio de comunicação como títulos de livros, como "Televisão e as Crianças" ou "Meios de Comunicação de Massa e Saúde Pública", ultimamente o foco mudou para questões de mediação e midiatização.

Tratar dos alcances e limites dos conceitos a partir de problemas e objetivos de pesquisa é um dos desafios teórico-metodológicos de um campo científico. Para tanto, o objetivo deste artigo é mostrar como o conceito de midiatização tem sido abordado por alguns autores e debater o seu potencial teórico para o estudo das classes sociais no campo da Comunicação, tema que tem sido investigado pelos autores Grohmann (2013b) e Mauro (2014), tentando estabelecer fronteiras e interfaces entre estudar as classes sociais como "mediação da comunicação" e as classes sociais "midiatizadas".

Nesta abordagem discutiremos: a) algumas relações entre classes sociais e comunicação; b) as diferentes abordagens do conceito de midiatização; c) as relações entre midiatização e mediação, sempre considerando como podem se desdobrar alguns problemas de pesquisa a partir desses conceitos.

\section{Classe social como tema da comunicação}

Entendemos o campo da comunicação como uma confluência de duas matrizes: uma social e uma discursiva/linguageira. A comunicação como atividade humana e como produção de sentido se dá por meio da linguagem (LEONTIEV, 2004): "os signos materializam a realidade viva. Entender comunicação sem os discursos e seus sentidos é perder a especificidade do comunicacional e de sua presença no cotidiano dos sujeitos sociais".

Por outro lado, compreender comunicação sem sociedade é fazer parte de uma ciência estéril. "Não há teoria da comunicação sem uma teoria implícita ou explícita de sociedade" (WOLTON, 2003, p. 16). Trata-se de uma práxis social e, portanto, depende dos valores e ideias em circulação na sociedade para produzir significados. Não se trata aqui de compreender a comunicação "das

1 "O trabalho informacional é material, pois é transformação, pelo corpo humano e sua mente, através de próteses adequadas (ferramentas e tecnologias), de materiais portadores de signos que contêm valor pelo signo que portam. Trabalho imaterial somente se for aquele feito por Deus no ato da criação" (DANTAS, 2012, p. 17-18). coisas" ou o "pós-humano", "imaterial" materializados na sociedade.

Não é só porque transformamos discursivamente as "classes sociais" em "indivíduos livres, leves e soltos" que elas deixaram de existir. "É fácil 'pensar que a classe não importa' se você permanece relativamente 'nãoafetado por privações e exclusões que ela causa'” (MURDOCK, 2009, p. 33).

Nos últimos anos, a ascensão financeira de uma camada da população brasileira, que ficou conhecida como "nova classe média" ou "nova classe C" - expressão 
lançada pelo economista Marcelo Neri (2010) -, ganhou destaque e teve ampla repercussão. Presenciou-se o reavivamento do tema "classes sociais" na mídia e no meio acadêmico brasileiro, em um contexto em que as classes sociais estão relegadas a segundo plano nas pesquisas acadêmicas, que tendem a ressaltar, de acordo com Murdock (2009), a pós-modernidade e o individualismo.

Pois as classes sociais (e nesse caso específico, esta parcela da população identificada como "nova classe média") estão representadas nas campanhas publicitárias, no jornalismo, no cinema, nos institutos de pesquisa, na internet, nas telenovelas, na conversa de bar e no almoço de família - como uma explosão de presença comunicacional-representacional das classes.

As telenovelas brasileiras Avenida Brasil (2012), de João Emanuel Carneiro, e Cheias de Charme (2012), de Filipe Miguez e Izabel de Oliveira, tiveram papel importante nessas representações. Ambas foram exibidas na Rede Globo, a primeira no horário nobre das 21 horas e a segunda, às 19 horas. Avenida Brasil ganhou espaço também na mídia internacional e foi apontada por Lopes e Mungioli (2013), no Anuário Obitel 2013, como um grande destaque de 2012, um fenômeno midiático e uma "narrativa da nação".

Embora ambas as produções tragam, entre outros elementos, aspectos puramente midiáticos de pouca consistência sociológica para validar o termo "nova classe C", é possível sugerir que telenovelas como essas colaboram com a construção de um sentido de classe social no Brasil, ainda mais se consideramos o potencial cultural da telenovela no país (MAURO, 2014).

A própria expressão "nova classe média", neste contexto, se tornou uma marca publicitária e política (GROHMANN, 2013a), inclusive de governo, procurando construir discursivamente e midiaticamente sujeitos sociais por meio de diferentes regimes de visibilidade e tentando produzir vínculos de identificação e reconhecimento.

Sociologicamente, como mostram Jessé Souza (2010) e Pochmann (2014), não se trata de uma classe: nem nova nem média. "Esse importante movimento social não se converteu, contudo, na constituição de uma nova classe social, tampouco permite que se enquadrem os novos consumidores no segmento da classe média" (POCHMANN, 2014, p. 71). Para o autor, trata-se da "recomposição da classe trabalhadora em novas bases de consumo". No sentido comunicacional, entretanto, cabe-nos indagar a produção de sentido em circulação dos termos discursivos "nova classe média" e "classe trabalhadora" para os sujeitos identificados como essa parcela da população.

Outro evento importante envolvendo comunicação e classes sociais, em 2013, foram os "rolezinhos", encontros em shopping centers de jovens da periferia, marcados pela internet (FIGARO; GROHMANN, 2014). Notícias de jornais publicaram declarações de medo e repúdio por parte da classe média e diretores dos estabelecimentos, trazendo à tona o debate em torno do tema "luta de classes", embora os jovens organizadores refutassem essa intenção:

Nas reportagens, os organizadores refutam que os "rolezinhos" sejam parte da "luta de classes". Pois o "fato em si" não pode realmente ser tomado como "luta de classes". Porém, a circulação do fato midiatizado nas redes sociais e em outros lugares faz dele um palco para a "luta de classes". (Ibid., p. 10)

Os casos trazem à tona a importância adquirida pela comunicação na discussão e produção de sentido a respeito das classes sociais no país. De certo modo, esses exemplos evocam aquilo que Stig Hjarvard (2014, p. 35) denomina como esfera pública da mídia, um espaço público aberto à representação pública e discussões 
de assuntos pertencentes a todas as instituições sociais. Na verdade, mais do que discussão, na situação específica dos "rolezinhos", as redes sociais digitais também tiveram papel-chave na organização do encontro dos jovens.

Apesar das diferenças, temos nos dois eventos a centralidade social cada vez maior da mídia e a consequente pertinência em estudar as classes sociais mediante tal fenômeno. Para tal fim, o conceito de midiatização tem se mostrado frutífero. O termo está sendo utilizado nas pesquisas em comunicação para abranger as transformações sociais que vem ocorrendo devido à crescente presença midiática na sociedade (COULDRY; HEPP, 2013).

De um modo amplo, "[...] midiatização é um conceito usado para analisar criticamente a inter-relação entre mudanças na mídia e comunicações por um lado, e mudanças na cultura e sociedade, por outro" (COULDRY; HEPP, 2013, p. 197).

$\mathrm{Na}$ verdade, existem diferentes vertentes de pesquisa e formas de conceber a midiatização. Alguns pesquisadores a entendem como um processo longo que tem acompanhado toda a história da humanidade; enquanto outros usam o termo para descrever o crescimento da relevância social e cultural da mídia desde a emergência da mídia de massa, como a imprensa, o rádio, o cinema e a televisão (Ibid.). Exploraremos a seguir alguns desses aspectos e as possibilidades teóricas para o estudo das classes sociais.

\section{Midiatização: diferentes abordagens}

De acordo com Couldry e Hepp (2013) existem duas correntes de estudo sobre a midiatização: a institucionalista e a tradição social-construtivista. Elas coexistem e estão se tornando cada vez mais convergentes. A primeira, que vem principalmente dos estudos do jornalismo e da comunicação política, enxerga a mídia como uma instituição mais ou menos independente com uma lógica própria, e entende a midiatização como uma adaptação de diferentes campos sociais às regras midiáticas institucionalizadas (Ibid.).

A vertente social-construtivista, por sua vez, entende o conceito como um processo de construção comunicativa da realidade social e cultural. Trata-se de uma concepção mais aberta que a lógica da mídia, pois enfatiza a complexidade da mídia como instituição e tecnologia (Ibid.).

Sobre as diferenças entre as duas tradições de pesquisa da midiatização, Andreas Hepp (2014) explica:

Ambas diferem em seu foco sobre como teorizar a midiatização: enquanto a tradição institucional tem, até recentemente, estado interessada principalmente na mídia tradicional de massa, cuja influência é descrita como uma lógica de mídia, a tradição socioconstrutivista está mais voltada às práticas de comunicação cotidianas - especialmente aquelas relacionadas à mídia digital e à comunicação pessoal - e enfoca a construção comunicativa em transformação da cultura e da sociedade. (Ibid., p. 47)

O pesquisador brasileiro José Luiz Braga faz parte da tradição social-construtivista. Para o autor, estamos vivendo uma transição de um processo interacional de referência da escrita para um processo interacional de referência midiatizado de base tecnológica. Um processo interacional de referência se refere não só à hegemonia e preferência por um modo de interação (o escrito, por exemplo), mas também considera que a sociedade é organizada através desse modo interativo (BRAGA, 2006).

De acordo com o autor, a midiatização pode ser relacionada a processos específicos que passam a se desenvolver de acordo com a mídia, como política, entretenimento, consumo, e também pode estar relacionada a um nível maior, 
no sentido de a própria sociedade estar midiatizada (Ibid.). De acordo com tal perspectiva, no que tange o estudo das classes sociais estaríamos abordando, é possível sugerir, processos específicos da sociedade relacionados às classes sociais, que passam a se desenvolver de acordo com a mídia.

No exemplo da "nova classe média", destacamos o papel fundamental da mídia de massa, tanto a jornalística como a teleficção, na disseminação de um sentido de classe que passou a ser discutido e percebido como realidade. Já no caso dos "rolezinhos", além da mídia de massa, o papel das redes sociais digitais se destacou na organização dos encontros, possibilitando a mobilização de indivíduos pertencentes a uma mesma realidade social. Essas peculiaridades demonstram que cada dispositivo tem suas especificidades nos processo de midiatização.

O teórico Andreas Hepp (2014), que aborda em seu artigo algumas possibilidades teóricas de aproximação entre as duas tradições de estudo - a institucional e a socioconstrutivista -, atenta para a importância de considerar essas diferenças entre as mídias. Segundo o pesquisador (Ibid., p. 51), o termo midiatização sugere aspectos quantitativos e qualitativos. Os primeiros estão relacionados à propagação temporal cada vez maior da midiatização e o segundo se refere justamente ao papel da especificidade de certas mídias nesse processo de mudança.

Desse modo, Hepp (2014) atenta para a necessidade de estudar a midiatização de forma mais abrangente, considerando as diversas mídias. Para isso, ele propõe o conceito de "mundos midiatizados", considerando a midiatização cotidiana. Para o autor, mundos midiatizados podem ser entendidos como certos "pequenos mundos da vida" ou "mundos sociais" que são articulados pela comunicação midiática. "Os mundos midiatizados são o nível no qual a midiatização se torna concreta e pode ser analisada empiricamente" (Ibid., p. 53).

Procurando operacionalizar a pesquisa na área de midiatização, objeto de programa de pesquisa na Alemanha, Hepp (2014) traz os conceitos de "forças de moldagem da mídia" e "configuração comunicativa". A metáfora das forças de moldagem significa uma aproximação entre as tradições institucionalista e socioconstrutivista: "Essa metáfora é usada para indicar que não podemos presumir um efeito geral ou livre de contexto da mídia específica; entretanto, diferentes mídias moldam a comunicação de formas diversas." (Ibid., p. 51).

Enquanto isso, o conceito de configuração procura compreender os "padrões de processos entrelaçando o que existe ao longo de várias mídias e em um 'enquadramento temático' que orienta a ação comunicativa." (Ibid., 56). As configurações comunicativas midiatizadas da "nova classe média" se referem, de alguma forma, em nossa visão, aos discursos hegemônicos relacionados aos aspectos identitários dessa parcela da população, discursos estes em circulação, seja pelas diferentes plataformas digitais ou pelas mídias tradicionais, como mostrado em Fígaro e Grohmann (2014).

Além disso, é pertinente também destacar alguns aspectos da perspectiva institucional que podem contribuir com o conceito de midiatização. Tomaremos o levantamento de dois tipos de midiatização nessa vertente, a saber: a direta e a indireta. A direta é quando uma determinada atividade passa a ser executada de uma forma diferente devido à mídia, como, por exemplo, jogar xadrez ou fazer transações bancárias pela internet. A forma indireta se refere à influência cada vez maior da mídia em uma determinada atividade, mas que não afeta diretamente o modo como as pessoas executam uma tarefa; trata-se de uma influência mais sutil (HJARVARD, 2012). 
sociedade. Por exemplo, o conhecimento dos brasileiros sobre os EUA também se deve às narrativas dos meios de comunicação (fato ou ficção) sobre o país; como consequência, as discussões políticas brasileiras sobre os EUA também estão entrelaçadas com representações midiáticas da cultura, dos costumes e da história norte-americanos. (Ibid., p. 67)

A forma indireta nos parece como hipótese a que mais se aproxima da midiatização do sentido de classe social no caso das notícias sobre a "nova classe média" e sua representação na telenovela, uma vez que houve a representação social da cultura brasileira que não interferiu, a priori, em modos específicos de realizar uma tarefa e sim nas formas de conhecimento social.

É possível dizer também que a perspectiva de midiatização indireta se assemelha à visão macrossocial abordada por Braga (2006), segundo a qual a sociedade constrói a realidade social através de processos interacionais pelos quais os indivíduos, grupos e setores da sociedade se relacionam.

A midiatização direta, por outro lado, poderia ser atribuída aos "rolezinhos", pois as redes sociais digitais modificaram, de certa forma, a maneira como os jovens se organizam para se encontrar. Tal perspectiva, em algum sentido, também dialoga com a tradição socioconstrutivista, pois, conforme já explicitado, de acordo com Hepp (2014, p. 47), tal vertente está mais focada às práticas cotidianas de comunicação e às mídias digitais.

As perspectivas da midiatização, - seja de acordo com a tradição institucionalista ou com a socioconstrutivista -, vale ressaltar, não devem ser encaradas como uma "teoria dos meios". Devem-se enfatizar as inter-relações entre as mudanças midiáticas e comunicacionais, por um lado, e na cultura e na sociedade, por outro (HEPP; KROTZ, 2014).

Contudo, é importante frisar, conforme abordado anteriormente, que a visão institucionalista concebe a mídia como uma força institucional semi-independente. Hjarvard explica que: "Nos últimos cem anos, os meios de comunicação se diferenciaram de outras práticas sociais e tornaram-se uma instituição separada da sociedade." (HJARVARD, 2014, p. 30).

Nessa perspectiva, Hjarvard (2014) expõe que a midiatização está relacionada às transformações institucionais da alta modernidade. Na posição deste autor (HJARVARD, 2012) a midiatização não é um processo universal, mas sim uma tendência que se acelerou nos últimos anos do século $X X$ nas sociedades modernas e desenvolvidas. $O$ estudioso atrela essa tendência às transformações da globalização, por isso é um processo que se dá de forma diferente em cada região do mundo. Essa visão se afasta de algumas vertentes da midiatização.

O pesquisador Eliseo Verón (2014) é um dos autores que não concorda com essa concepção. Para este teórico, a midiatização é o resultado da capacidade humana de semiose, que se expressa em fenômenos midiáticos, constituindo uma característica universal de todas as sociedades humanas.

O autor traz uma perspectiva de longo prazo, cuja vantagem para ele é "[...] nos relembrar que o que está acontecendo nas sociedades da modernidade tardia começou, de fato, há muito tempo." (Ibid., p. 16). O estudioso define a midiatização como a nomenclatura dada a uma longa sequência de fenômenos midiáticos que são institucionalizados nas sociedades. Apesar das divergências, os dois pesquisadores concordam com o fato de os processos de midiatização não serem lineares e com a alteração provocada na noção de tempo. Verón (2014, p. 16-17) fala da aceleração do tempo histórico e de um processo de descontextualização do significado, enquanto Hjarvard (2014, p. 31) aborda a diferenciação e o desencaixe do tempo e espaço. 
O fato é que o caráter de mudança está presente tanto na visão mais abrangente de Verón (2014), que considera grandes transformações ao longo da história, quanto de Hjarvard (2014), que delimita a midiatização como um processo de transformação da modernidade tardia.

Além de Hjarvard (2012; 2014) e Verón (2014), os outros estudiosos da midiatização citados neste trabalho concordam, em algum sentido, com o caráter de mudança que o termo carrega. Braga (2006), ao abordá-la como um processo incompleto transparece o caráter de mudança do fenômeno, que está vinculado às demandas e transformações tecnológicas dos meios de comunicação e às novas formas de interações sociais. Inclusive, o caráter de mudança que o termo midiatização traz é um dos fatores que o diferencia do conceito de mediação, como veremos a seguir.

\section{Midiatização e mediação}

O conceito de mediação possui tradição na pesquisa em comunicação principalmente nos estudos britânicos, a partir da influência de Raymond Williams (1992) e de Roger Silverstone (2002), e na América Latina, a partir dos estudos de Jesús Martín-Barbero (2009).

Raymond Williams (1992) coloca a importância do termo "mediação" para refutar a teoria do reflexo, que relaciona a comunicação à mera transmissão. Para o autor, a mediação está relacionada "aos processos de composição necessários, em um determinado meio; como tal, indica as relações práticas sociais e artísticas. Em seus usos mais comuns, porém, refere-se a um modo indireto de relação entre a experiência e sua composição" (WILLIAMS, 1992, p. 24).

Da área de Comunicação, Roger Silverstone (2002) pensa o conceito de mediação como um processo, que implica em movimento e circulação de significados, que são nômades e, portanto, transformados. Esse processo é semelhante ao de uma tradução, que envolve, sempre, em alguma medida, uma "agressão", como "a violência que fazemos aos significados alheios, mesmo nas mais suaves tentativas de compreender" (Ibid., p. 35). A partir desse conceito de mediação, que é trabalhado por grupos, instituições e tecnologias, podemos:

perceber que a mídia se estende para além do ponto de contato entre os textos midiáticos e seus leitores ou espectadores. É necessário considerar que ela envolve os produtores e consumidores de mídia numa atividade mais ou menos contínua de engajamento e desengajamento com significados que têm sua fonte ou seu foco nos textos mediados, mas que dilatam a experiência e são avaliados à sua luz numa infinidade de maneiras (Ibid., p. 33)

Com a morte prematura de Silverstone, em 2006, o potencial teórico do conceito de mediação foi, em alguma medida, relegado a segundo plano para os britânicos. De certa forma, podemos falar que o conceito de "mediação" pode ser considerado como pertencente à tradição latino-americana da pesquisa em comunicação, como bem mostra Lopes (2014), mais ligada às "epistemologias do Sul" (SANTOS; MENESES, 2010) do que à hegemonia europeia.

A obra de Martín-Barbero, nesse cenário, é crucial, na qual todo o processo de comunicação é articulado a partir das mediações, entendendo que o eixo do debate deve se deslocar para onde a produção de sentido em comunicação é efetivamente construída, a partir dos nexos do próprio processo de comunicação.

Em vez de fazer a pesquisa partir da análise das lógicas de produção e recepção, para depois procurar suas relações de imbricação ou enfrentamento, propomos partir das mediações, isto é, dos lugares dos quais provêm as construções que 
delimitam e configuram a materialidade social e a expressividade cultural da [mídia]. (MARTíN-BARBERO, 2009, p. 294)

As críticas ao conceito de "mediação" passam pela imprecisão conceitual, seja na obra de Martín-Barbero (SIGNATES, 2006), seja pela própria imprecisão semântica e linguística que o termo carrega em diferentes idiomas (LIVINGSTONE, 2009). Há que se considerar também que, em alguns casos, o conceito de midiatização de um autor pode se assemelhar ao conceito de mediação de outro, como os de Hjarvard (2012) e Silverstone (2002), respectivamente.

Mas, como afirma Couldry (2012), é preciso focar menos em uma discussão puramente terminológica e pensar mais nos tipos de explicação a que cada conceito se propõe. Podemos compreender, então, os conceitos de "mediação" e "midiatização" como diferentes, porém complementares, atuando em diferentes esferas teóricas da comunicação. "A mediação continua a ser um termo importante para compreender como a mídia molda o mundo social que [...] complementa utilmente a teoria da midiatização" (COULDRY, 2008, p. 381). Em um mundo onde há a "mediação de tudo" (LIVINGSTONE, 2009), focalizar os esforços em "mini mundos" (HEPP; KROTZ, 2014) específicos pode ser útil para que haja um maior aprofundamento do processo.

Para Lopes (2014), o conceito de mediação traz um protagonismo mais do âmbito do comunicacional do que propriamente do midiático. A autora enxerga maior proximidade com a noção de midiatização no conceito de "mediação comunicativa da cultura" (MARTíN-BARBERO, 2009).

Hepp (2014) também diferencia os dois termos. Ele argumenta que a mediação descreve características gerais de qualquer processo de comunicação de mídia, enquanto a midiatização é um termo que teoriza a mudança relacionada à mídia. Enquanto a mediação se refere ao processo de "construção de sentido", a midiatização descreve este processo de mudança, refletindo como o processo de mediação tem se modificado com a emergência dos diferentes dispositivos midiáticos.

Couldry e Hepp (2013) também exprimem o aspecto de transformação embutido no conceito de midiatização quando o opõe ao significado de mediação. Enquanto este último se refere, para os autores, ao processo de comunicação em geral, midiatização designa mudança. "Midiatização reflete como as consequências globais de múltiplos processos de mediação têm mudado com a emergência de diferentes tipos de mídia." (Ibid., p. 197).

Hjarvard, por sua vez, expõe que sua visão de midiatização dialoga com noção de mediação do teórico Jesús Martin-Barbero (2009), porém, ele enfatiza que a teoria da midiatização aponta para algo adicional: "[...] que as mídias, como estruturas, ou seja, práticas institucionalizadas, conseguiram impulso próprio, o que cada vez mais influencia outras esferas sociais." (HJARVARD, 2014, p. 26). Para o estudioso, a midiatização diz respeito a transformações estruturais de longa duração na relação entre mídia e outras esferas sociais, diferente de mediação que aborda o uso da mídia para práticas comunicativas específicas em interação situada.

Marco Bastos (2012) complementa essa visão, mostrando como alguns autores, principalmente Strömbäck (2008), consideram a mediação como uma fase inicial da midiatização.

Essa fase inicial da midiatização ocorre sempre que os meios de comunicação de massa tornam-se a fonte principal em um determinado recorte social. [...] A mediação, com isso, seria um estágio sempre inicial e necessário para os estágios ulteriores de midiatização, que evoluem continuamente para um quadro de crescente dependência das audiências para com a mídia (BASTOS, 2012, p. 67) 
De algum modo, então, podemos considerar, de forma sucinta, que a mediação se refere a um processo de nível mais geral, da ordem do comunicacional, enquanto a midiatização se refere a processos de mudanças, de ordem do midiático e do social, em um nível de escala menor, considerando os dois conceitos como complementares e que envolvem a questão da circulação. Cabe-nos agora, apontar alguns possíveis desdobramentos de pesquisa das classes sociais a partir da "mediação" e da "midiatização".

No primeiro caso, trata-se de considerar a classe social como mediação fundamental da comunicação, procurando responder à pergunta: em que medida os processos de comunicação passam pelo "filtro" ou "enquadramento" da classe? Como as diferentes leituras e representações expressam esses enquadramentos? Trata-se de "olhar com os óculos da classe" a partir do processo comunicacional.

O trabalho de Veneza Ronsini (2012) pode ser considerado um exemplo de como podemos estudar as classes a partir da mediação. Em seu livro, a autora mostra como jovens de diferentes classes veem telenovelas da Rede Globo e como suas leituras acerca da pobreza e da desigualdade refletem, em certa medida, as suas posições de classe. Os discursos dos jovens sobre as novelas na pesquisa não estão midiatizados, mas, até enquanto linguagem, eles se encontram mediados pela questão da classe.

Por outro lado, para a compreensão das classes sociais midiatizadas é preciso compreender, de alguma forma, a questão da mudança. Outro problema possível, além dos que foram discutidos ao longo do texto, envolve explorar, em que medida a incorporação das diferentes mídias em uma determinada classe social significa mudanças também nas esferas sociais e culturais. Exemplo: em que medida o crescente uso de internet pelo celular e a utilização das redes sociais pelas classes populares revelam uma mudança também nos valores e nas ideologias desta parcela da população? Ou ainda: qual o papel das mídias para uma mudança ou uma reprodução do social?

\section{Considerações finais}

Couldry (2014) afirma que um dos erros constantes sobre a "era digital" é a negligência da questão do "social" em si, ou então a substituição dessa esfera por "um discurso sobre como as redes atravessam espaços e nos conectam uns aos outros de determinadas maneiras" (Ibid., p. 68). Por isso, é preciso compreender a midiatização das classes a partir dos detalhes, do "chão da pesquisa empírica", ou nas palavras do autor, "when mediatization hits the ground" (Ibid., p. 54).

Esse "chão" faz com que também se evite cair em uma teoria celebratória da midiatização, ou nas palavras de Lynn Clark (2014, p. 315), "um leve determinismo tecnológico", pois, como nos mostra Marko Ampuja (2011), há uma midiatização da própria teoria social (ou de parcela dela) a partir da influência de acadêmicos ligados à teoria da "sociedade da informação", teoria dos meios, teorias pósmodernas e teorias da globalização.

Quando grandes utopias sociais foram declaradas impossíveis, e quando o poder do capital parece mais consolidado do que nunca, a crença na natureza revolucionária das novas mídias se realiza na crença de que ainda estamos no limiar da mudança milenar que está cheia de possibilidades. Assim, eu diria que o vazio de imaginação utópica na academia, criado pela hegemonia neoliberal, encontra a sua expressão na recente midiatização da teoria social e cultural, na emergência contundente de argumentos em relação a mudanças de tecnológicasmidiáticas e suas consequências socioculturais radicais (Ibid., p. 297)

É preciso, pois, não tomar o conceito de midiatização como um determinismo tecnológico nem naturalizá-lo, tomá-lo como dado, mas sim entendê-lo de 
maneira dialética a partir da mudança e da reprodução de valores tanto nas esferas midiáticas e comunicacionais, como nas esferas sociais e culturais. Para além das correntes institucionalistas e social-construtivistas, seria possível pensar a midiatização a partir de uma perspectiva dialético-materialista?

Como desafio futuro, principalmente no que concerne aos estudos que envolvem midiatização e classes sociais, concordamos com Lynn Clark (2014): é preciso pensar na midiatização não somente como a contribuição para a pesquisa em comunicação, mas também em qual o papel do pesquisador em midiatização para a mudança social.

\section{Referências Bibliográficas}

AMPUJA, M. Globalization theory, media-centrism and neoliberalism: a critique of recent intellectual trends. Critical Sociology, v. 38, n. 2, p. 281-301, 2011.

BASTOS, M. T. Medium, media, mediação e midiatização: a perspectiva germânica. In: MATTOS, M. Â.; JANOTTI JUNIOR, J.; JACKS, N. (Orgs.). Mediação \& midiatização. Salvador: Edufba; Brasília: Compós, 2012, p. 53-77.

BRAGA, J. L. Sobre mediatização como processo interacional de referência. In: Encontro Anual da Associação Nacional dos Programas de Pós-graduação em Comunicação - Compós, 2006, Bauru (SP). Anais XV Compós Encontro Anual da Associação Nacional dos Programas de Pós-Graduação em Comunicação. São Paulo: Compós, 2006. p.16.

CLARK, L. S. Mediatization: concluding thoughts and challenges for the future. In: HEPP, A.; KROTZ, F. (Orgs.). Mediatized worlds: culture and society in a media age. Londres: Palgrave, 2014, p. 307-322.

COULDRY, N. Mediatization or mediation? Alternative understandings of the emergent space of digital storytelling. New Media Society, v. 10, n. 3, p. 373-391, 2008. Polity, 2012.

Media, society, world: social theory and digital media practice. Londres:

. When mediatization hits the ground. In: HEPP, A.; KROTZ, F. (Orgs.). Mediatized worlds: culture and society in a media age. Londres: Palgrave, 2014, p. 54-70.

COULDRY, N.; HEPP, A. Conceptualizing mediatization: contexts, traditions, arguments. Communication Theory, v. 23, n. 3, p. 191-201, 2013.

DANTAS, M. Trabalho com Informação: valor, acumulação, apropriação nas redes do capital. Rio de Janeiro: UFRJ, 2012.

FIGARO, R.; GROHMANN, R. Lutas de classes e os "rolezinhos": uma abordagem na perspectiva dos estudos de recepção. In: Encontro Anual da Associação Nacional dos Programas de Pós-Graduação em Comunicação - Compós, 2014, Belém, PA. Anais XXIII Compós Encontro Anual da Associação Nacional dos Programas de Pós-Graduação em Comunicação. Belém: Compós, 2014.

GROHMANN, R. A midiatização da nova classe média: identidades discursivas na revista IstoÉ Dinheiro. In: Congresso Internacional de Comunicação e Consumo Comunicon 2013. Anais do Comunicon 2013. São Paulo: 2013a. 
HEPP, A. As configurações comunicativas de mundos midiatizados: pesquisa da midiatização na era da "mediação de tudo". Matrizes, São Paulo, v. 8, n. 1, p. 2144, jan./jun. 2014.

HEPP, A.; KROTZ, F. (Orgs.). Mediatized worlds: culture and society in a media age. Londres: Palgrave, 2014.

HJARVARD, S. Midiatização: teorizando a mídia como agente de mudança social e cultural. Matrizes, São Paulo, v. 5, n. 2, p. 53-92, jan./jun. 2012.

- Midiatização: conceituando a mudança social e cultural. Matrizes, São Paulo, v. 8, n. 1, p. 21-44, jan./jun. 2014.

LELO, T.; GROHMANN, R. A diversidade do conceito de circulação nos estudos em comunicação. ECCOM - Educação, Cultura e Comunicação, v. 5, n. 9, p. 21-34, jan./jun. 2014.

LEONTIEV, A. O Desenvolvimento do Psiquismo. São Paulo: Centauro, 2004.

LIVINGSTONE, S. On the mediation of everything: ICA presidential address 2008. Journal of Communication, v. 59, n. 1, p. 1-18, 2009.

LOPES, M. I. V. de. Mediação e recepção: algumas conexões teóricas e metodológicas nos estudos latino-americanos de comunicação. Matrizes, São Paulo, v. 8, n. 1, p. 21-44, jan./jun. 2014.

LOPES, M. I. V. de; MUNGIOLI, M. C. P. Brasil: a telenovela como fenômeno midiático. In: LOPES, M. I. V. de.; GÓMEZ, G. O. (Orgs.). OBITEL 2013: memória social e fiçcão televisiva em países Ibero-americanos. Porto Alegre: Sulina, 2013.

MARTIN-BARBERO, J. Dos meios às mediações: comunicação, cultura e hegemonia. Tradução de Ronald Polito e Sérgio Alcides. Rio de Janeiro: UFRJ, 2009.

MATTOS, M. Â.; JANOTTI JUNIOR, J.; JACKS, N. (Orgs.). Mediação \& Midiatização. Salvador: Edufba; Brasília: Compós, 2012.

MAURO, R. Aspectos da midiatização do consumo e do sentido de classe social na telenovela: a representação da "nova classe C". 2104, 159 p. (Mestrado em Ciências da Comunicação) - Escola de Comunicação e Artes, Universidade de São Paulo, São Paulo, 2014.

MURDOCK, G. Comunicação contemporânea e questões de classe. Matrizes, São Paulo, v. 2 n. 2, p. 31-56, 2009.

NERI, M. C. (Coord.). A nova classe média: o lado brilhante dos pobres. Rio de Janeiro: CPS/FGV, 2010.

POCHMANN, M. O mito da grande classe média: capitalismo e estrutura social. São Paulo: Boitempo, 2014.

RONSINI, V. A crença no mérito e a desigualdade: a recepção da telenovela do horário nobre. Porto Alegre: Sulina, 2012.

SANTOS, B. S.; MENESES, M. P. (Orgs.). Epistemologias do Sul. São Paulo: Cortez, 2010.

SIGNATES, L. Estudo sobre o conceito de mediação e sua validade como categoria de análise para os estudos de comunicação. In: SOUSA, M. W. (Orgs.). Recepção Midiática e Espaço Público: novos olhares. São Paulo: Paulinas, 2006. 
SILVERSTONE, R. Por que estudar a mídia? São Paulo: Loyola, 2002.

SOUZA, J. Os batalhadores brasileiros: nova classe média ou nova classe trabalhadora? Belo Horizonte: UFMG, 2010.

STRÖMBÄCK, J. Four phases of mediatization: an analysis of the mediatization of politics. The International Journal of Press/Politics, v. 13, n. 3, p. 228-246, jul. 2008. VERÓN, E. Teoria da midiatização: uma perspectiva semioantropológica e algumas de suas consequências. Matrizes, São Paulo, v. 8, n. 1, p. 13-19, jan./jun. 2014.

WILLIAMS, R. Cultura. Rio de Janeiro: Paz e Terra, 1992.

WOLTON, D. Internet, e depois? Uma teoria crítica das novas mídias. Porto Alegre: Sulina, 2003. 